\title{
AMBIENTES INTERACTIVOS MEDIADOS POR LAS TIC: INNOVACIÓN DEL DESARROLLO AUDITIVO Y COMUNICATIVO DE LA POBLACIÓN CON DEFICIENCIA AUDITIVA
}

\section{INTERACTIVE ENVIRONMENTS MEDIATED BY ICT: INNOVATION OF THE AUDITIVE AND COMMUNICATIVE DEVELOPMENT OF THE POPULATION WITH HEARING DEFICIENCY}

\author{
Carlos Julio Parra Castro1, Ángela Marcela Castellanos Barbosa², Luis Ernesto Pardo Rodríguez³ \\ Recibido para publicación: 31 de enero de 2017 - Aceptado para publicación: 19 de marzo 2017
}

\begin{abstract}
RESUMEN
Este artículo describe el desarrollo de "Escúchame" un software on line creado con la intención de mejorar progresivamente el desempeño de personas con disminución en su capacidad auditiva y comunicativa por medio de actividades lúdicas e interactivas que integren al niño como usuario y la familia como agente social primario. El objetivo es fortalecer la creación de herramientas interactivas de bajo costo, que sean accesibles tanto a las personas con disminución en su capacidad auditiva y comunicativa, a las familias y a los especialistas en el tema.
\end{abstract}

Palabras claves: Ambientes interactivos, tecnología, herramientas interactivas, sub- habilidades comunicativas

\begin{abstract}
This article presents the development of "Escúchame", an online software created with the intention of progressively upgrade the perfomance of people with difficulties in listening and communicating by means of leisure and interactive activities, which integrate the kid as user and the family as primary social agent. The objective is to strenght the creation of low-price interactive tools, that can be avaiable not only for people with disabilities by listening and communicating, but also for their families and specialists of the subject.
\end{abstract}

Keywords: Interactive environments, technology, interactive tools, sub-communicative habilities.

\footnotetext{
${ }_{1}^{1}$ Ingeniero de Sistemas, Universidad Distrital Francisco José de Caldas. Magíster en Sistemas de Información, Universidad de Los Andes. Director ejecutivo Etraining SAS

2 Maestrante en Literatura, Pontificia Universidad Javeriana. Maestrante en Educación, Universidad Pedagógica Nacional. Comunicadora social, Universidad Central. Profesora Universitaria e Investigadora.

${ }^{3}$ Candidato a Doctor, Doctorado en Educación y Sociedad, Universidad de La Salle. Magíster en Docencia, Universidad de La Salle. Especialista en Pedagogía de la Comunicación, Universidad Distrital Francisco José de Caldas. Bibliotecólogo y Archivista, Universidad de La Salle.
} 


\section{INTRODUCCIÓN}

El desarrollo auditivo y comunicativo de la población con deficiencia auditiva y comunicativa, usuaria de ayudas con el apoyo de ambientes interactivos mediados por las TIC, ha significado pensar la tecnología digital como una posibilidad de inclusión para personas con dificultades auditivas y comunicativas a través de la creación de innovaciones y desarrollos tecnológicos como aporte a la solución de dichos problemas. Así, este artículo da cuenta del desarrollo de "Escúchame" un software on line que permite el mejoramiento progresivo del desempeño de personas con disminución en su capacidad auditiva y comunicativa por medio de actividades lúdicas e interactivas. Mediante este proyecto se pretende aportar una solución que genere opciones para que los usuarios puedan integrarse a la vida laboral, cultural, educativa y social.

Esta iniciativa tiene como punto de partida la insuficiencia de recursos y posibilidades para rehabilitar o mejorar las habilidades auditivas y comunicativas de personas que han recibido un implante coclear; este es un dispositivo médico electrónico que realiza el trabajo de las partes dañadas del oído interno (cóclea) para proporcionar señales sonoras al cerebro. Las personas implantadas y/o en proceso de recuperación; requieren una serie de terapias que les ayudan a ingresar o reingresar al mundo de los sonidos. En este proceso se evidenció que el uso de herramientas tecnológicas es insuficiente en el área y la poca tecnología digital disponible relacionada con las problemáticas en salud auditiva, es foránea, de alto costo e inaccesible para la población afectada. Por ello, "Escúchame" comprende desde ambientes interactivos, las necesidades de la población con disminución de la capacidad auditiva y proyecta alternativas a de uso de las nuevas tecnologías como recursos que contribuyan al mejoramiento de la calidad de vida de las personas con deficiencias auditivas y comunicativas.

Es preciso reconocer que las organizaciones responsables de atender esta problemática en el país son: El Instituto Nacional para Sordos (INSOR) la Clínica José A. Rivas (Bogotá), la Fundación CINDA (Bogotá), el centro Pro-débiles auditivos (Medellín), la Clínica de occidente (Medellín), el Instituto para niños ciegos y sordos del Valle del Cauca (Cali) y Te oigo Centro Audiológico (Barranquilla), sin embargo hay pocas instituciones de salud dedicadas a soluciones con TIC y las tecnologías existentes no abordan el problema desde una perspectiva integral auditivo-comunicativo. De manera que, el software "Escúchame" se configura como una solución integral que combina aspectos físicos, digitales y de investigación, al servicio de la población con disminución de su capacidad auditiva y/o comunicativa, inscrita en el marco de las iniciativas de Medicina Inteligente en su modalidad de asistencia médica a distancia.

Este proyecto tiene como objetivo desarrollar un software on line para el mejoramiento progresivo de las personas con disminución en su capacidad auditiva y comunicativa con base en actividades lúdicas e interactivas que integren al niño como usuario y la familia como agente social primario con el fin de crear herramientas interactivas de bajo costo, que sean accesibles tanto a las personas con disminución en su capacidad auditiva y comunicativa, a las familias y a los especialistas que lo requieran.

Ha sido posible por la unión de voluntades institucionales de la Corporación Unificada Nacional de Educación Superior - CUN, Y Etraining SAS empresa dedicada a la innovación con Tecnologías de la Información y las comunicaciones y se espera que el proyecto contribuya a integrar saberes interdisciplinarios desde la Fonoaudiología, los Sistemas de Información, la comunicación aumentativa y los modelos educativos.

\section{CONTEXTO DE LA INVESTIGACIÓN}

La deficiencia auditiva y de comunicación y la falta de audición son carencias auditivas cuyo impacto es a menudo infravalorado debido al hecho de su poca visibilidad, sin embargo, no poder oír supone una dificultad grave de comunicación, que se fundamenta en el lenguaje oral. Cualquier alteración de la comunicación conlleva al aislamiento social por cuanto la persona que no oye no entiende fácilmente a los que le hablan, pero su interlocutor tampoco logra hacerse entender por la persona con pérdida auditiva.

El desarrollo de la tecnología informática significa un cambio radical en esta dinámica con un salto cualitativo en la invención de ayudas tecnológicas. La última generación de prótesis auditivas ofrece 
audición funcional (es decir de la capacidad de entender el lenguaje oral sin ayuda de la lectura labial) a las personas con deficiencia auditiva moderada a severa y el implante coclear consigue lo mismo para las personas con deficiencia auditiva severa y profunda adquirida; para los niños con deficiencia auditiva severa y profunda que no alcanzan beneficios con las prótesis auditivas convencionales si se implantan precozmente.

La disposición de audición funcional desde la infancia significa para los niños que han nacido con una deficiencia auditiva profunda la oportunidad de acceder al lenguaje oral de una forma casi natural, les abre la oportunidad integrarse en los entornos: social, escolar y laboral. En la actualidad, es posible proporcionarles un nivel de audición tan eficaz como la de cualquier otro niño lo que cambia es la forma de acceder al sonido y a la información. El auge de la innovación tecnológica ha influido también en los métodos de enseñanza, permitiendo mayor versatilidad en la presentación y el acceso a los contenidos, así como la potenciación de medios alternativos por ejemplo visualización de parámetros de la voz y del habla, la automatización de sistemas de aprendizaje.

La tecnología supone ahora una herramienta importante en la eliminación de barreras y debe aplicarse de la misma manera a las personas con discapacidad, disminuyendo el impacto de ésta cuando es posible y proporcionándole los medios de compensación necesarios y al mismo tiempo, el entorno social, generalizando a todos los ámbitos la aplicación de recursos técnicos y apoyando los programas de desarrollo de tecnologías cada vez más eficaces.

En el caso de las personas con discapacidad auditiva usuarias de ayudas tecnológicas (audífonos y/o implantes coleares) para desarrollar sus habilidades auditivas y comunicativas requieren de un proceso de rehabilitación que les oriente el paso a paso del proceso. En la actualidad en el ámbito internacional existen algunos recursos tecnológicos tipo programas o software que facilitan dicho proceso y orientan a los padres en el desarrollo del mismo, sin embargo, son de difícil acceso.

En el contexto mundial, los datos de la Organización Mundial de la Salud OMS describen que el $60 \%$ de la pérdida de audición es prevenible; el " $8 \%$ de otras causas - abarca las malformaciones congénitas, no genéticas y otras causas prenatales de origen materno, $4 \%$ por medicamentos ototóxicos, $31 \%$ debido a enfermedades infecciosas, paperas, rubeola, meningitis, sarampión e infecciones de oído, y un $17 \%$ por causas relacionadas con el nacimiento, complicaciones de parto, prematuridad y bajo peso al nacer". (Colombia. Minsalud, 2017, p. 3-4) (OMS, 2016).

Las insuficiencias en la salud auditiva pueden generar en los individuos dificultad para establecer interacciones sociales constructivas, ambientes hostiles y poco solidarios, bajo rendimiento académico e intelectual, con el consecuente aislamiento en ambientes proclives a tolerar las diferencias o las discapacidades, actitudes negativas hacia el desarrollo personal, dificultades para la superación de situaciones adversas, disminución de la integración social y baja autoestima, todo ello redunda en la disminución de la calidad de vida de los individuos.

En el ámbito nacional la realidad tecnológica que se ofrece en este campo no cubre ninguno los aspectos de la rehabilitación por tanto el acercamiento a estos programas, especialmente a los niños que viven en territorios alejados de cabeceras municipales y por tanto de profesionales en el área de la fonoaudiología capacitados para el trabajo con esta población, la existencia de una herramienta tecnológica que facilite la adquisición de habilidades facilita y contribuye de gran manera a la comunicación oral y a la calidad de vida de la población sorda.

\section{CONTEXTO TECNOLÓGICO}

Se identificó que, en el ámbito tecnológico, se cuenta con elementos de tecnología asistiva que brinda herramientas para mejorar la calidad de vida de las personas con deficiencias auditivas y de comunicación. En Colombia, Jorge Enrique Leal desarrolló una plataforma que traduce el español al lenguaje de señas que utilizan los sordos. Leal creó "Hetah" que cuenta con un avatar de mujer llamada Iris, que gesticula las señas de manera clara para personas con discapacidad auditiva. La plataforma fue diseñada con el propósito de romper las barreras de comunicación entre personas oyentes y personas sordas. (Leal, J. E., 2017).

Desde la acción estatal el Ministerio de Tecnologías de la Información y las Comunicaciones se propone 
"Garantizar espacios incluyentes y accesibles como un desafío que genera grandes dividendos sociales que no solo incentiva la creatividad, sino que ayuda a impulsar la innovación, el emprendimiento y la participación ciudadana"; en esta descripción se clasifica la herramienta Centro de Relevo. (Ministerio de Tecnologías de la Información y las Comunicaciones, 2017). El servicio está disponible desde las 6 a.m. hasta la medianoche en www.centroderelevo. gov.co o la aplicación móvil Centro de Relevo Live Connect para lo cual el usuario debe tener activa la cámara web de su dispositivo. Teniendo en cuenta lo anterior se pensó en aplicaciones tecnológicas para la rehabilitación de personas sordas usuarias de ayudas auditivas en el país y se propuso el desarrollo e implementación de un software lúdico e interactivo basado en el uso de tecnologías para mejorar el desempeño auditivo y comunicativo de la población con deficiencia auditiva usuaria de ayudas auditivas como una contribución a la rehabilitación para profesionales que se desempeñen en este campo y los familiares del entorno de este tipo de población. (Ministerio de Tecnologías de la Información y las Comunicaciones, 2017).

\section{CONTEXTO TEÓRICO: TECNOLOGÍAS DE AYUDA}

Antonio Ferrer y Francisco Alcantud definen las tecnologías de ayuda: objeto, artefacto, instrumento, o equipo parcial o global, sistema comercial o adaptado a individuos con deficiencias auditivas para mejorar o aumentar sus capacidades funcionales. En las deficiencias auditivas se consideran la particularidad de cada individuo con respecto a sus carencias, cada instrumento se aplica a una circunstancia única, en función de la naturaleza y grado de discapacidad. (Ferrer Manchón, A. M., 2003, p. 2-3).

Las tecnologías de ayuda se clasifican dos grupos en función de sus objetivos, las técnicas aumentativas; cuya función consiste en restituir la función auditiva por medio de implantes quirúrgicos, audífonos, prótesis bucles magnéticos que permitan tener accesibilidad de la información mediante estímulos visuales o de vibración en artefactos tecnológicos como teléfonos, relojes, computadores, entre otros.

El uso de tecnologías en el ámbito de la informática y la computación han posibilitado el desarrollo de técnicas visuales y de percepción táctil; en este sentido, sus objetivos pueden ser múltiples, desde mejorar aspectos del habla, estimular niveles del lenguaje (el vocabulario, los marcadores morfológicos, la sintaxis, entre otros), o para el desarrollo de la lengua de signos. (Alcantud Marín, F., 2002, p. 20-22).

Los programas que han sido creados siguen la línea de acción en su preocupación por el desarrollo del lenguaje desde los estímulos gráficos a través de la pantalla. La mayoría de innovaciones desde la creación de software es útil en tareas de estudio, educación y rehabilitación del habla. (Alcantud Marín, F., 2002, p. 20-22).

Dentro de los objetivos propuestos desde la informática y el diseño de software se encuentran los de aumentar conocimiento de la presencia de sonido, controlar la vocalización sostenida a intensidad especificada, discriminar diferentes grados de intensidad y potenciar su control tanto para incrementar como para disminuir, aumentar definición de sílabas en personas que las omiten, marcando los distintos golpes de voz, mostrar diferencias entre sonidos sordos- sonoros. Es importante tener en cuenta que existen materiales de formación como diccionarios de la lengua de signos y los materiales de apoyo para el aprendizaje de la lengua de signos.

\section{AVANCES TECNOLÓGICOS DE APOYO PARA PERSONAS CON DEFICIENCIA AUDITIVA $Y$ COMUNICATIVA}

Esta revisión da cuenta de los avances tecnológicos, teniendo en cuenta estudios de prospectiva y vigilancia tecnológica. A continuación, se describen experiencias investigativas fundamentadas, revisiones documentadas que cubre un rango cronológico de doce años, desde 2006 hasta 2017. Se configura un recorrido temático sobre la relación entre deficiencias auditivas y comunicativas, sordera, nuevas tecnologías y la rehabilitación auditiva.

Las experiencias investigativas referenciadas son: Sistema AVEL y el Sistema IMASON.

\subsection{Sistema AVEL}

El sistema AVEL es un Analizador de vocales 
para la educación del lenguaje. Es un programa de reconocimiento de voz apoyado con una tarjeta analógica incrustada en el computador, es un componente independiente del Método de Instrumentación MEST - Método de Estimulación Sono-Táctil concebido por el fonoaudiólogo D. Julio Sanjuán, diseñado por EGESA, Electrónica General Española S.A. y distribuido por ORTOTESCA, S.L. Es un dispositivo electrónico con tarjeta de reconocimiento de voz, relés vibratorios y software específico para la intervención logopédica. (González Rus, G., 2007) (Monfort, M., et al. 2006).

La unidad AVEL está estructurado mediante tres componentes:

Tabla 1. Componente 1, Programas de Articulación Vocálica.

\begin{tabular}{|c|c|c|}
\hline \multicolumn{3}{|c|}{$\begin{array}{l}\text { Sistema AVEL } \\
\text { Analizador de vocales para la educación del lenguaje. }\end{array}$} \\
\hline COMPONENTE 1 & ESTRUCTURA & DESCRIPCIÓN \\
\hline $\begin{array}{l}\text { Programas de } \\
\text { Articulación Vocálica. } \\
\text { Enfocados a la } \\
\text { pronunciación y } \\
\text { desmutización del } \\
\text { individuo por medio de } \\
\text { patrones de intensidad, } \\
\text { tonalidad y duración. }\end{array}$ & $\begin{array}{l}\text { Desmutización vocalización } \\
\text { Ejercicios de ritmo 1-2-3 } \\
\text { Juego con Avelino }\end{array}$ & $\begin{array}{l}\text { Integra reconocimiento de sonidos, cuerpo humano, ruidos } \\
\text { de animales, de la casa, de la calle; sonidos de instrumentos } \\
\text { musicales; reconocimiento de vocales, palabras monosilábicas, } \\
\text { bisilábicas y trisilábicas y onomatopeyas. } \\
\text { Reconocimiento de manifestaciones o ausencia de sonido. } \\
\text { Tres aplicaciones para la imitación de patrones vocálicos con } \\
\text { un tiempo y velocidad determinada. El propósito es mejorar la } \\
\text { fluidez y corrección articulatoria. } \\
\text { Programa de afianzamiento de la vocalización/desmutización. } \\
\text { Avelino, el personaje, recorre la pantalla y cuando el paciente } \\
\text { articula correctamente una vocal, el, lo mira y posiciona la boca } \\
\text { con la vocal emitida. El propósito es reforzar el punto y modo de } \\
\text { articulatorio para conseguir la pronunciación correcta de cada } \\
\text { vocal. } \\
\text { Dispositivo que indica el compás de las composiciones } \\
\text { musicales basado en dos luces que se prenden y apagan a } \\
\text { ritmos configurables, el propósito, afianzar la articulación. }\end{array}$ \\
\hline
\end{tabular}

Elaboración propia con base en González Rus, G., (2007). Recuperado de http://bit.ly/2vEVzi

Tabla 2. Componente 2, Juego de refuerzo a la vocalización.

\begin{tabular}{|c|c|c|}
\hline COMPONENTE 2 & ESTRUCTURA & DESCRIPCIÓN \\
\hline $\begin{array}{l}\text { Juegos de refuerzo } \\
\text { a la vocalización. } \\
\text { Aplicaciones que animan } \\
\text { al niño a las dinámicas } \\
\text { de aprendizaje del } \\
\text { programa por medio del } \\
\text { juego }\end{array}$ & $\begin{array}{l}\text { Coloreado de dibujos } \\
\text { Juegos de encestar vocales } \\
\text { Juego de pinchar los globos } \\
\text { Juego del laberinto }\end{array}$ & $\begin{array}{l}\text { El niño dibuja cada sección del dibujo, articulando vocales y } \\
\text { consonantes fricativas. La intención es potenciar en el niño la } \\
\text { emisión vocálica mediante acciones lúdicas. } \\
\text { El juego consiste en cambiar el número de pelotas presentadas, } \\
\text { la velocidad de desplazamiento y el tiempo de permanencia en } \\
\text { la pantalla. El objetivo es afianzar la vocalización del niño. } \\
\text { El niño pincha los globos que se presentan en la pantalla. } \\
\text { Se pretende desarrollar la articulación vocálica y afianzar los } \\
\text { resonadores. } \\
\text { El juego se apoya en un muñeco que se desplaza por una playa } \\
\text { hasta que coge un objeto. Se controla el movimiento con la } \\
\text { pronunciación de cuatro vocales una por cada dirección de los } \\
\text { cuatro puntos cardinales. }\end{array}$ \\
\hline
\end{tabular}

Elaboración propia con base en González Rus, G., (2007). Recuperado de http://bit.ly/2vEVzis 
Tabla 3. Componente 3, Programas complementarios.

\begin{tabular}{|c|c|c|}
\hline COMPONENTE 3 & ESTRUCTURA & DESCRIPCIÓN \\
\hline $\begin{array}{l}\text { Programas } \\
\text { complementarios al } \\
\text { trabajo del Logopeda. } \\
\text { Aplicaciones que } \\
\text { controlan las sesiones, } \\
\text { de medición de la } \\
\text { ventana auditiva, de } \\
\text { medición del paciente en } \\
\text { torno a un patrón. }\end{array}$ & $\begin{array}{l}\text { Gráficas de intensidad y } \\
\text { tono v. } 1 \text { y v.2 } \\
\text { Juegos de asociación } 1 \text { y } 2\end{array}$ & $\begin{array}{l}\text { Posibilita la depuración del sonido y muestra la frase que se } \\
\text { está trabajando, la idea es que el paciente pueda leer al tiempo } \\
\text { que imita el modelo del Logopeda. La finalidad es identificar } \\
\text { el uso adecuado y correcto de la voz en pacientes disfónicos. } \\
\text { Ejercicios enfocados a realizar asociaciones de dificultad } \\
\text { progresiva atendiendo uno o varios criterios: colores, palabras } \\
\text { o las dos, con el uso exclusivo de la vocalización. La meta es } \\
\text { desarrollar las estructuras semánticas en el lenguaje oral. } \\
\text { Prueba de audiometría tonal en campo libre por medio de dibujos } \\
\text { animados que aparecen en la pantalla. El fin es posibilitar la } \\
\text { realización de audiometrías a pacientes de corta edad. } \\
\text { Constituido por una escala sonora a través de la cual el paciente } \\
\text { expresa las sensaciones que percibe. Pretende la rehabilitación } \\
\text { de implantados. }\end{array}$ \\
\hline
\end{tabular}

Elaboración propia con base en González Rus, G., (2007). Recuperado de http://bit.ly/2vEVzis

La variedad de componentes y estructura del Sistema AVEL, aplicación de trabajo de acciones con los rasgos fonológicos del castellano que permite que el paciente y el especialista a cargo de los procesos de rehabilitación tengan a su alcance herramientas de trabajo basadas en test, pruebas de audiometría, juegos de asociación, gráficas, dinámicas lúdicas, ejercicios auditivos y ejercicios de ritmo. El objetivo del Sistema es facilitar el diagnóstico de las deficiencias auditivas y comunicativas en pacientes de corta edad, así como su rehabilitación mediante el uso adecuado de la voz.

\subsection{IMASON}

IMASON es un software especializado que tiene el objetivo de mejorar la percepción auditiva de personas con deficiencias auditivas y de comunicación. Es un programa que asocia el sonido con la imagen, su potencial consiste en hacer un trabajo discriminado de sonidos. Las actividades pedagógicas que se desarrollan con este software atienden la identificación de sonidos aislados y en conjunto, igualmente potencia la memoria tanto auditiva como visual de manera secuencial y aleatoria invitando a la asociación de sonidos con imágenes de la pantalla. (Galiana Sanchís, J., 2006, p. 1) El programa IMASON está estructurado de la siguiente manera:

Tabla 4. IMANSION, Componentes.

\begin{tabular}{|c|c|c|}
\hline \multicolumn{3}{|c|}{$\begin{array}{l}\text { IMASON } \\
\text { Programa de discriminación y memoria auditiva }\end{array}$} \\
\hline COMPONENTES & ESTRUCTURA & DESCRIPCIÓN \\
\hline $\begin{array}{l}\text { 1. Identificación de } \\
\text { sonidos. Atiende las } \\
\text { dificultades de } \\
\text { movilidad. }\end{array}$ & $\begin{array}{l}\text { Panel interactivo entre } \\
\text { sonidos e imágenes }\end{array}$ & $\begin{array}{l}\text { Se oye un sonido, en la parte central de la pantalla pasan } \\
\text { imágenes. El paciente pulsará el ratón cuando crea que la } \\
\text { imagen corresponde al sonido emitido. Se configura el tiempo } \\
\text { de respuesta de } 1 \text { a } 15 \text { segundos. }\end{array}$ \\
\hline $\begin{array}{l}\text { 2. Loto. Enfocado } \\
\text { en la habilidad de } \\
\text { discriminación. }\end{array}$ & $\begin{array}{l}\text { Lista de imágenes } \\
\text { preestablecidas. }\end{array}$ & $\begin{array}{l}\text { Este ejercicio requiere de un entrenamiento en el que se oyen } \\
\text { los sonidos seleccionados. Se presiona el botón Comenzar, se } \\
\text { escucha un sonido, el paciente selecciona en el computador la } \\
\text { imagen correspondiente al sonido. La diferencia con el anterior } \\
\text { es que, en este, en la pantalla habrá una serie imágenes ya } \\
\text { establecidas. El programa informa sobre aciertos, errores e } \\
\text { intentos de la actividad. }\end{array}$ \\
\hline
\end{tabular}




\begin{tabular}{|c|c|c|}
\hline COMPONENTES & ESTRUCTURA & DESCRIPCIÓN \\
\hline $\begin{array}{l}\text { 3. Memoria auditiva } 1 . \\
\text { Centrado en la habilidad } \\
\text { de memoria secuencial. }\end{array}$ & $\begin{array}{c}\text { Secuencia diferencial de } \\
\text { imágenes }\end{array}$ & $\begin{array}{l}\text { En pantalla aparecen diferentes imágenes; se oyen los sonidos } \\
\text { correspondientes a esas imágenes de forma secuencial y } \\
\text { aleatoriamente. Una vez escuchados todos, se deberá pulsar } \\
\text { las imágenes en la misma secuencia que han aparecido los } \\
\text { sonidos. El programa informa sobre aciertos, errores e intentos } \\
\text { al realizar la actividad. }\end{array}$ \\
\hline $\begin{array}{l}\text { 4. Memoria auditiva } 2 \\
\text { Orienta la habilidad de } \\
\text { memoria aleatoria. }\end{array}$ & $\begin{array}{l}\text { Lista de imágenes } \\
\text { intermitentes }\end{array}$ & $\begin{array}{l}\text { Secuencia de en la pantalla durante varios segundos; se borran } \\
\text { y se escuchan los sonidos de forma secuencial y aleatoria. El } \\
\text { paciente asociará el orden de los sonidos escuchados con la } \\
\text { respectiva imagen. El programa informa sobre los aciertos, } \\
\text { errores e intentos de la actividad. Se configura el tiempo de } \\
\text { respuesta de } 2 \text { a } 40 \text { segundos. }\end{array}$ \\
\hline $\begin{array}{l}\text { 5. Memoria auditiva } 3 . \\
\text { Despierta la habilidad de } \\
\text { comprensión auditiva. }\end{array}$ & $\begin{array}{l}\text { Lista de sonidos } \\
\text { intermitentes }\end{array}$ & $\begin{array}{l}\text { Se presentan imágenes y después se esconde un sonido, se } \\
\text { elige la imagen correspondiente con los sonidos. El programa } \\
\text { informa aciertos, errores e intentos de la actividad. }\end{array}$ \\
\hline
\end{tabular}

Elaboración propia con base en (Galiana Sanchís, J., 2006, p. 1) http://bit.ly/2uNzEcv

La percepción, discriminación y memoria auditiva, son el objetivo fundamental del programa IMASON. Con este programa el logopeda decide el dato sonoro y la imagen que requiera con el tiempo más conveniente. Además, puede trabajar a distancia y observar el proceso del niño. Una de las características esenciales del programa es que no está diseñado para un nivel educativo específico, puede trabajarse en cualquier edad y en diferentes deficiencias auditivas y comunicativas. Por ser un programa abierto, una imagen puede tener asociado más de un sonido y se pueden incluir las imágenes y sonidos que se deseen. Vale la pena recordar que el programa guarda automáticamente el informe de aciertos y errores del usuario. (Galiana Sanchís, J., 2006, p. 1).

\section{SOFTWARE ON LINE PARA LA (RE) HABILITACIÓN AUDITIVA}

El propósito del proyecto de investigación fue desarrollar un software interactivo como herramienta de apoyo en la estimulación y potenciación de destrezas mentales básicas para favorecer los procesos de aprendizaje con enfoque en competencias auditivas y comunicativas para un óptimo desarrollo cognitivo de los pacientes usuarios de ayudas auditivas.

\subsection{Componentes de la solución}

Los componentes de la solución contienen los parámetros fundamentales, estos son: registro Web, caracterización (evaluación), desarrollo
Auditivo y comunicativo (aprendizaje, evaluación), seguimiento y Control (resultados), administración, informes, y auditoría.

\subsection{Especificaciones minimas}

Estructura y diseño de la aplicación online:

Página de Inicio: En la página de inicio se encuentra el formulario para el registro de usuarios que luego serán aprobado por el administrador de la plataforma También se encuentra el formulario de acceso a la plataforma para los usuarios que ya están registrados y aprobados.

Panel de control de usuario: El usuario accede a esta página luego de ingresar sus credenciales de acceso en la página inicial de la plataforma en la cual el usuario podrá acceder al primer módulo de diagnóstico el cual permitirá saber en qué condiciones y capacidades se encuentra el usuario para iniciar su proceso en el desarrollo y mejora de su capacidad auditiva.

Roles: visitante, acompañante, paciente con deficiencia auditiva, especialista en el área de salud, administrador, superadministrador.

Copias de Seguridad y Respaldo: Las copias se realizarán de acuerdo con el crecimiento de la información, aprovechando el espacio en disco para decidir que tantas copias se deben tener, las cuales serán incrementales diarias y semanalmente. 
Apariencia de la aplicación web: se manejó un entorno de reconocimiento intuitivo en el cual el usuario realice un reconocimiento de los elementos propios de la herramienta según el enfoque pedagógico, En esta tecnología se aplicaron elementos VRML (Virtual Reality Modeling Language). De acuerdo con los estándares de tecnologías actuales la aplicación cuenta con elementos tales como un diseño convergente, que permite su uso en diferentes medios electrónicos como tablets, smartphone, pantallas táctiles, desarrollado en html5, css3, e interacción con Javascript, con formatos de imagen png, .jpg, mov, flv, avi, mpg, objetos con atributos para trabajos en dimensionamiento e interacción.

\subsection{Diseño}

El Aplicativo tiene un diseño multiplataforma definido por Etraining, cuenta con aplicaciones interactivas que permiten a los visitantes de forma fácil y dinámica acceder a todas las actividades propuestas: elementos interactivos para desarrollo auditivo y comunicativo: elementos gráficos en $3 \mathrm{D}$, mundo virtual en $3 \mathrm{D}$, audio espectro $3 \mathrm{D}$, tutor virtual, gráficas y reportes de avance.

\subsection{Descripción de módulos}

\subsubsection{Registro Web}

El registro Web es el primer paso que realiza un prospecto de usuarios del aplicativo, entendiendo por prospecto el usuario que entrará a utilizar el software. En este paso el prospecto accede por medio de un explorador a la aplicación usando el enlace en la Internet.

\subsubsection{Inducción}

Si la persona ha sido aprobada por el administrador del sistema, se dará inicio a un proceso de inducción del software para que el usuario obtenga los conocimientos básicos para el uso de la plataforma. Para ello debe acceder nuevamente al sitio con un enlace que envía por correo electrónico el sistema y que le permitirá entrar al módulo de inducción del software.

Este módulo está diseñado para tener en cuenta las siguientes temáticas: acceso a la Internet, aspectos y restricciones del sistema, módulos, descripción general del proceso de aprendizaje, consulta de avance, consulta de seguimiento y recomendaciones, informes generales del sistema.

\subsubsection{Caracterización}

El siguiente paso después de la inducción es el proceso de la caracterización, donde el usuario aprobado entra a ser evaluado determinando el nivel correspondiente al desarrollo actual y actividades a ejecutar.

\subsubsection{Desarrollo auditivo}

Es el módulo en el que el usuario deberá cumplir con las actividades propuestas por el sistema con el objetivo de desarrollar sus habilidades auditivas. Dichas actividades contarán con elementos tales como mundos virtuales en 3D, elementos gráficos en 3D, Tutor Virtual, audio en espectro 3D y diversos elementos interactivos que refuercen las estrategias planteadas.

Esté módulo estará estructurar en las siguientes habilidades auditivas, definidas en el numeral 12 de este documento:

- Detección: habilidad para escuchar presencia o ausencia de sonidos. Es el primer paso para el aprendizaje auditivo y de ella dependen los niveles más altos de procesamiento.

- Discriminación: habilidad para comparar si dos sonidos son iguales o diferentes. Para esta tarea es necesario que los pacientes manejen dichos conceptos o que se le presenten tareas donde haya sólo dos estímulos en juego. Cuando se realicen este tipo de tareas hay que tener en cuenta que únicamente se están comparando dos estímulos entre sí.

- Identificación: habilidad para responder correctamente en un conjunto cerrado de opciones. Se basa en la posibilidad de utilizar ciertos rasgos acústicos del habla para seleccionar un estímulo dentro de una serie de opciones. Ya no se trata de una mera comparación dado que tiene que haber, por lo menos, más de dos estímulos presentes. La diferenciación entre Identificación y Reconocimiento se basa en cómo se realizan las tareas, ya sea en formato cerrado (Ios pacientes tienen los estímulos presentes 0 saben con certeza cuáles van a ser las opciones que se les van a presentar auditivamente).

- Reconocimiento: habilidad para responder adecuadamente utilizando solamente la audición, sin la ayuda de ningún contexto. Esta habilidad es muy superior a la identificación dado que los pacientes no tienen ningún referente y por lo tanto tienen que valerse de su conocimiento, del contexto acústico y 
lingüístico y de la información almacenada en su memoria auditiva para responder.

- Comprensión: habilidad para entender y dar respuestas interactivas más no imitativas o repetitivas. Esta habilidad le va a permitir a los niños procesar la información que recibe por audición para construir el significado de las palabras y para decodificar los mensajes. Esta habilidad no es estrictamente auditiva ya que entran en juego otras áreas de procesamiento más complejas, además de la audición. Hay que tener en cuenta que la comprensión auditiva es el mecanismo por el cual se puede utilizar la audición no sólo para la decodificación de los mensajes sino para el desarrollo semántico, gramatical, morfológico y fonológico del lenguaje. Una vez que haya adquirido la habilidad para comprender el lenguaje auditivamente los pacientes podrán adquirir información nueva a través de la audición sin necesidad acceder a ella primero a través de otros sentidos, como la vista.

- La comprensión auditiva es un requisito para que se empleen el canal auditivo como principal para la adquisición del lenguaje y esto se puede lograr en aquellos niños cuyo canal auditivo se restablece o habilita de forma temprana, siempre que no existan problemas específicos para el procesamiento de las señales auditivas o un trastorno para la comprensión del lenguaje concomitante con la discapacidad auditiva.

\subsubsection{Seguimiento y control}

El seguimiento se realiza sobre el progreso del usuario el cual será supervisado por acompañante o especialista; Para ello el sistema presentará información relevante de los avances, permitiendo un control al especialista sobre cómo debe ser el acompañamiento, teniendo el récord y generando alarmas sobre el mismo.

\subsubsection{Administración}

- Gestión De Roles. Este módulo permite crear los perfiles para el acceso a diferentes funciones del software de acuerdo con el perfil definido en el rol.

- Aprobación y registro de Usuarios. En este módulo el administrador aprueba al visitante que realizó el registro web validándolo como usuario.

- Gestión de actividades y contenidos.

\subsubsection{Informes}

El módulo de reportes permite generar informes sobre el desarrollo auditivo de los usuarios, el manejo de la plataforma, informes de estadísticas de uso y acceso a la plataforma.

\subsubsection{Auditoría}

Registro de las acciones de usuario en el sistema que permite generar un histórico de todas las acciones ejecutadas.

\subsubsection{Características funcionales generales}

Es una aplicación web donde se podrá encontrar:

- Aplicación interactiva, en espacios con dimensiones físicas para el desarrollo auditivo y comunicativo.

- Gestión con alarmas del progreso de reconocimiento auditivo y comunicativo, teniendo presente varios factores como por ejemplo el tiempo, el no avance.

- Gestión sobre evaluación de habilidad determinado en niveles.

- Gestión, seguimiento, control y asesoramiento sobre el acompañante en el progreso del niño en desarrollo.

\subsubsection{Características funcionales}

- Opera vía web siendo adaptativo a cualquier dispositivo con acceso a la Internet.

- Interactúa con la persona a la cual desea hacer un desarrollo auditivo y comunicativo, por medio de elementos multimedia y espacios dimensionales.

- Registra en forma de historia médica de progreso en habilidades comunicativas y auditivas.

- Genera encuestas de satisfacción de cumplimiento del objetivo y progreso de cada actividad cumplida teniendo presente el tiempo efectuado, Aclaración: el software puede generar dicha información.

- Envía alarmas de bajo progreso o no está en capacidad de desarrollar la actividad propuesta.

- Identifica el no avance por impedimentos imprevistos resueltos por tutorial de inicio en la aplicación.

- Diagnostica en el módulo preliminar la habilidad estilo test interactivo y capaz de determinar varios niveles que pueden ser cognitivos o por rangos de edad.

- Monitorea niveles en el "desarrollo del lenguaje" con hitos, el cual el sistema realiza un seguimiento. 
- Controla el seguimiento y asesoramiento sobre el trabajo realizado por el acompañante de la persona que efectúa el desarrollo auditivo.

- Administra usuarios, crear, modificar activar y modificar los roles de cada uno de los usuarios del software.

\subsubsection{Características no funcionales}

Instalación y configuración d módulos, instalación y configuración de módulos en el servidor provisto. Configuración de parámetros generales y roles de seguridad que facilitarán la administración del contenido del sitio. Instalación y configuración de módulos necesarios para cumplir los casos de uso. Carga de contenidos de portal del sitio actual en la nueva implementación.

\section{ENTREGABLES:}

- Aplicación instalada y corriendo en el servidor.

- Documento de Especificaciones de Requerimientos funcionales y no funcionales. - Documento de Arquitectura del aplicativo (Diseño, Capas, Estilos, estándares y estilo de programación).

- Garantía y soporte sobre lo entregado por el tiempo estimado. Esto no incluye implementación de nuevos requerimientos después de entregada la solución.

\subsection{Infraestructura de la solución}

La solución cuenta con 2 componentes principales los cuales pueden correr en una sola máquina. Sin embargo, se sugiere que corran en diferentes máquinas (pueden ser máquinas virtuales) y cada máquina virtual en diferentes discos duros y dos proveedores de Internet para garantizar desempeño y la disponibilidad requerida en el proyecto. Respecto al almacenamiento idealmente se recomienda SSD, que facilitará la administración de espacio en disco y adicionalmente este dispositivo se usará como repositorio de todos los documentos del portal.

\section{METODOLOGÍA}

La metodología utilizada para el diseño de software será la metodología RUP la cual contempla cinco fases de desarrollo: Modelado de negocio, requisitos, análisis y diseño, implementación, pruebas y despliegue. Se utilizará en conjunto con UML que permite definir a través de diferentes diagramas las funcionalidades vistas y componentes del software.

\section{Tecnologías}

Se utilizó el siguiente conjunto de herramientas: HTML, PHP, JavaScript y CSS como tecnologías para la interacción de los usuarios de con la solución de información. SQL Server como tecnología para el almacenamiento de la información.

\section{Patrón de diseño modelo vista controlador}

- El software está bajo el modelo vista controlador en el cual se separan por capas que incluye vista, controlador, estructura de datos

- Datos o Modelo de datos: Es el componente encargado de almacenar y definir la estructura de datos

- Presentación o Vista: Es toda la información que se puede consultar u observar, visualizada un explorador web.

- Controlador: Componente que tiene la lógica y que recibe la solicitud del cliente y consulta la base de datos procesa los datos da la orden de envío de los datos procesados al cliente.

\section{CONCLUSIONES}

Este desarrollo del software "Escúchame" permitió pensar y aplicar la tecnología digital como posibilidad de inclusión para personas con dificultades auditivas y de comunicación. De esta manera se vinculan los desarrollos e innovaciones tecnológicas como aporte a la solución de problemas de audición.

Se evidenció que el uso de herramientas tecnológicas es insuficiente en el área y la escasa tecnología digital relacionada con las problemáticas en salud auditiva, es foránea, de alto costo e inaccesible para la población afectada.

Finalmente se reconoce que la tecnología supone la creación de herramientas para la inclusión en la vida cotidiana de personas con deficiencias auditivas y de comunicación con el fin de disminuir el impacto que significa la discapacidad permanente. 


\section{REFERENCIAS}

[1]. Alcantud Marín, F. (2000). Las tecnologías de ayuda: un modelo de intervención. Valencia: Universidad de Valencia. 25 p. Recuperado de http://bit.ly/2tYs8KC

[2]. Alcantud Marín, F. (2003). Las Tecnologías de la Información y de la Comunicación y los Trastornos Generalizados del Desarrollo. Salamanca: Servicio de información sobre discapacidad. 15 p. Recuperado de http:// bit.ly/2sBclbt

[3]. Colombia. Ministerio de Salud. (2017). ABECÉ. Salud auditiva y comunicativa. "Somos todos oídos". Bogotá: Minsalud. 10 p. Recuperado de http://bit.ly/2uYTfCn

[4]. Colombia. Ministerio de salud. (2016). Análisis de la situación de la salud auditiva y comunicativa en Colombia. Convenio 519 de 2015. Bogotá: Minsalud. Dirección de promoción y prevención. Subdirección de enfermedades no transmisibles. 274 p. Recuperado de http://bit.ly/2vqn7ru

[5]. Colombia. Ministerio de Tecnologías de la Información y las Comunicaciones. (2017). Las TIC cada vez más cerca de los colombianos en condición de discapacidad. Bogotá, El Ministerio. Recuperado de http:// bit.ly/2uShzFV
[6]. Ferrer Manchón, A. M., (2003). Las Tecnologías de Ayuda en la respuesta educativa del niño con discapacidad auditiva. Murcia; Universidad de Murcia. 27 p. Recuperado de http://bit.ly/2tYSjAF

[7]. Galiana Sanchís, J. (2006), IMASON (imágenes y sonidos) programa de discriminación y memoria auditiva. $2^{\circ}$ Encuentro Internacional. Trabajo de bajo coste. Adaptaciones elaboradas por usuarios. Recursos de libre acceso. Valencia, España. 15 p.| Recuperado de http://bit.ly/2uNzEcv

[8]. González Rus, G., (2007). Sistema AVEL: Vocalización. Speech Viewer III. MetaVox. Logopedia Interactiva. Di. Globus y Globus 2. Fonología. Talk it. Recuperado de http:// bit.ly/2vEVzis

[9]. Leal, J. E. (2017) Traductor a lengua de señas Versión 2.0. Recuperado de https:// hetah.net/

[10]. OMS. (2016). Pérdida de audición en la niñez. Ginebra, Suiza: Organización Mundial de la salud. Recuperado de http:// bit.ly/1OMbtcc 